\title{
Correction to: Implement of an automated unmanned recording system for tracking objects on mobile phones by image processing method
}

\author{
Byeongtae Ahn ${ }^{1} \cdot$ Hwa-Young Jeong ${ }^{2}$ (D)
}

Published online: 17 January 2020

(C) Springer Science+Business Media, LLC, part of Springer Nature 2020

\section{Correction to: Multimedia Tools Applications (2019) https://doi.org/10.1007/s11042-019-08556-3}

In the original publication, figure 2 was incorrect. The original article has been corrected.

Publisher's note Springer Nature remains neutral with regard to jurisdictional claims in published maps and institutional affiliations.

The online version of the original article can be found at https://doi.org/10.1007/s11042-019-08556-3

Hwa-Young Jeong

hyjeong@khu.ac.kr

Byeongtae Ahn

bt@ anyang.ac.kr

1 Liberal and Arts College, Anyang University, 22, 37-Beongil, Samdeok-Ro, Manan-Gu, Anyang City 430-714 Gyeonggi-do, Republic of Korea

2 Humanitas College, Kyung Hee University, 1 Hoegi-dong, Dongdaemun-gu, Seoul 130-701, Republic of Korea 